\title{
Reasons Why Policies Change in Nigeria
}

\author{
Benjamin Isah \\ Department of Political Science, University of Jos, Jos, Plateau State, Nigeria
}

Email address:

benjamiisah@gmail.com

To cite this article:

Benjamin Isah. Reasons Why Policies Change in Nigeria. Journal of Public Policy and Administration. Vol. 4, No. 2, 2020 , pp. $24-28$. doi: $10.11648 /$ j.jppa.20200402.12

Received: December 24, 2019; Accepted: January 17, 2020; Published: May 29, 2020

\begin{abstract}
This paper aimed at exploring reasons to why policies change in Nigeria. It defined policy as action taken toward problem solving by government or an organization. It also defined policy change as the replacement of one or more existing policies with another. The paper adopted advocacy coalition framework as theoretical frame work and explained policy change. The theory explained that policy change occurs through interactions between wide external changes or shocks to the political system and the success of the ideas in the coalitions, which may cause actors in the advocacy coalition to shift coalitions. More so, the paper discussed six reasons to why policies change in Nigeria, these reasons are: failure of the existing policy to accomplish it set objective, political instability, ineffective and corrupt political leadership, policy diffusion, change in structure and socio-economic factors. And finally the paper recommended that for a policy to fully achieve its set goal and objective, there should be continuity of policy implementation irrespective of the person or political party in office, proper assessment and implementation of policy will also reduce the risk of policy failure and also policy makers should have the people at heart and not use the predicament of the people for personal gain.
\end{abstract}

Keywords: Policy, Change, Policy Change

\section{Background of the Study}

Change is what is common to every individual and every society. It is one of those human elements that is constant. In another words, change is inevitable in every human society. The changes that occur in all aspect of human society can either be positive or negative change. Having understood that change is an inevitable aspect of mankind, the field of policy studies also tried to view the relevance of this phenomenon (policy change) in its academic discourse. It is understood that organizations, business enterprises as well as governments do change their policies in one way or the other in order to effectively achieve a set goals. The question here is: why do governments at different levels or organizations try to change policy/policies that is/are undergoing implementation process or an existing policy? This question is the concern of this paper. The paper will focus on exploring reasons to policy changes in Nigeria. But before then, let us first of all operationalize the concept of 'policy', 'change' and 'policy change'.

\section{Definition of Key Concept}

\subsection{Meaning of Policy}

The concept of policy has been defined by different scholars of public policy, but must of the definitions when observed, share things in common. Let us briefly consider some of the definitions given by some scholars. According to Obamwonmi [3], a policy is a response to the problems of people and society. a policy is "an intention, a guide to action, encompassing values which set priority and relations" [3]." Policies are course of actions or programs of actions which are chosen from among several alternatives by certain actors in response to certain problems." [3]. A policy may be referred to as the process of making relevant institutional and organisations decisions which include the identification of different alternatives such as programs or priorities on expenditures, and making choices among them based on the impact they will have [3]. The term "policy" refers to a standard set of principles that guide a course of action [5]. Looking at the above definitions of policy critically, one may see that they all have something in 
common. All the definitions in one way or the other acknowledged that policy has to do action taken toward problem solving.

Generally, we can classify policy into public and private policy. Public policies are established by the government, whereas private or institutional policies are created by organizations for institutional use. Many public policies are legally binding, meaning that individuals and institutions in the public and private sectors must comply with them. In contrast, policies created by private institutions do not carry the force of law; however, within an institution, compliance with such policies may be required [5].

\subsection{Meaning of Change}

Change is the core business of all sciences, from biology and genetics to anthropology and sociology. The question is: why, when, and how does change occur, and what does such change really mean? Trying to provide answers to such questions is the unending task of all involved in the field of scientific study, and this is also true when it comes to explaining policy change [1]. The very concept of 'change' refers to an empirical observation of difference in form, quality or state in time of a specific entity [7]. In another words, we can say that change refers to the process of becoming different. Therefore, we can briefly articulate these definitions by saying that change has to do with total transformation of things, events, phenomenon, etc. into another form different from the way it used to be prior to the transformation.

\subsection{Meaning of Policy Change}

First of all, it is important to distinguish 'policy change' from 'policy reform' as the terms are often used interchangeably in the literature. Policy change refers to incremental shifts in existing structures, or new and innovative policies Bennett and Howlett [2]. Reform usually refers to a major policy change. To take the example of health care, reform is 'the process of improving the performance of existing systems and of assuring their efficient and equitable response to future changes'[2] Change is a major part of our lives, whether it is change in industries, technologies or various sectors such as transportation, education, health care or social policies. But we still know little about when and how change occur [2]. Policy change means the replacement of one or more existing policies with one or more other policies. New policies can be adopted, the existing ones can be changed, or also terminated [8].

\section{Theoretical Framework}

Theories are set of propositions which seek to explain phenomena. There are different theories that tried to explain the reason why policy change in a given society. Examples of these theories are path dependence, advocacy coalition framework, policy learning, policy diffusion, punctuated equilibrium, institutional change, multi-level governance etc. when one studied these theories, one may find out that they are also reasons for policy change. For the purpose of this study, advocacy coalition framework is adopted, the reason being that it seems to explain the reasons behind policy change in Nigeria best as it proffers multiple and diverse explanations that suit Nigeria's situation in policy change.

\subsection{Advocacy Coalition Framework (ACF)}

Advocacy coalition framework is theoretical framework that explained policy change. The theory was developed to study policy process in North America, Europe and Asia [5]. The model comprises of many parts: there is a relatively stable system, external subsystem events, long term coalition opportunity structures, political subsystem, short term and constrains. It specifies that there are sets of core ideas about causation and value in public policy; these coalitions form because certain interests are linked to them. It is possible to map these networks of actors within a policy sector. 'Change comes from the ability of these ideas to adapt, ranging around a whole series of operational questions and what works in any one time or place' John [2]. Policy change occurs through interactions between wide external changes or shocks to the political system and the success of the ideas in the coalitions, which may cause actors in the advocacy coalition to shift coalitions.

ACF postulated that coalition seeking to induced their beliefs in to policy always compete with each other in the policy subsystem by using design methods in influencing government officials and policy makers. The belief and strategic behavior of the coalition groups significantly influence the output of a policy and its impact. The process of the competition among the coalition is affected by both long- and short-term opportunities, constraints and resources. These factors also in turn are affected by both relatively stable parameters and external subsystem events.

The relatively stable parameters include the basic attribute of the problem area and the distribution of natural resources, Fundamental sociocultural values and social structure with basic constitutional structure. All these parameters affect and cause change in socioeconomic condition, public opinions, systemic governing coalition and other policy subsystem.

What are the factors that make coalition groups induce their beliefs and demands in the policy subsystem? These factors include socioeconomic, public opinion, change in governing system and the activities of the policy subsystem itself. All these influence policy change, transformation or even making of a new one to address those problems. 


\subsection{General Model of Policy Change}

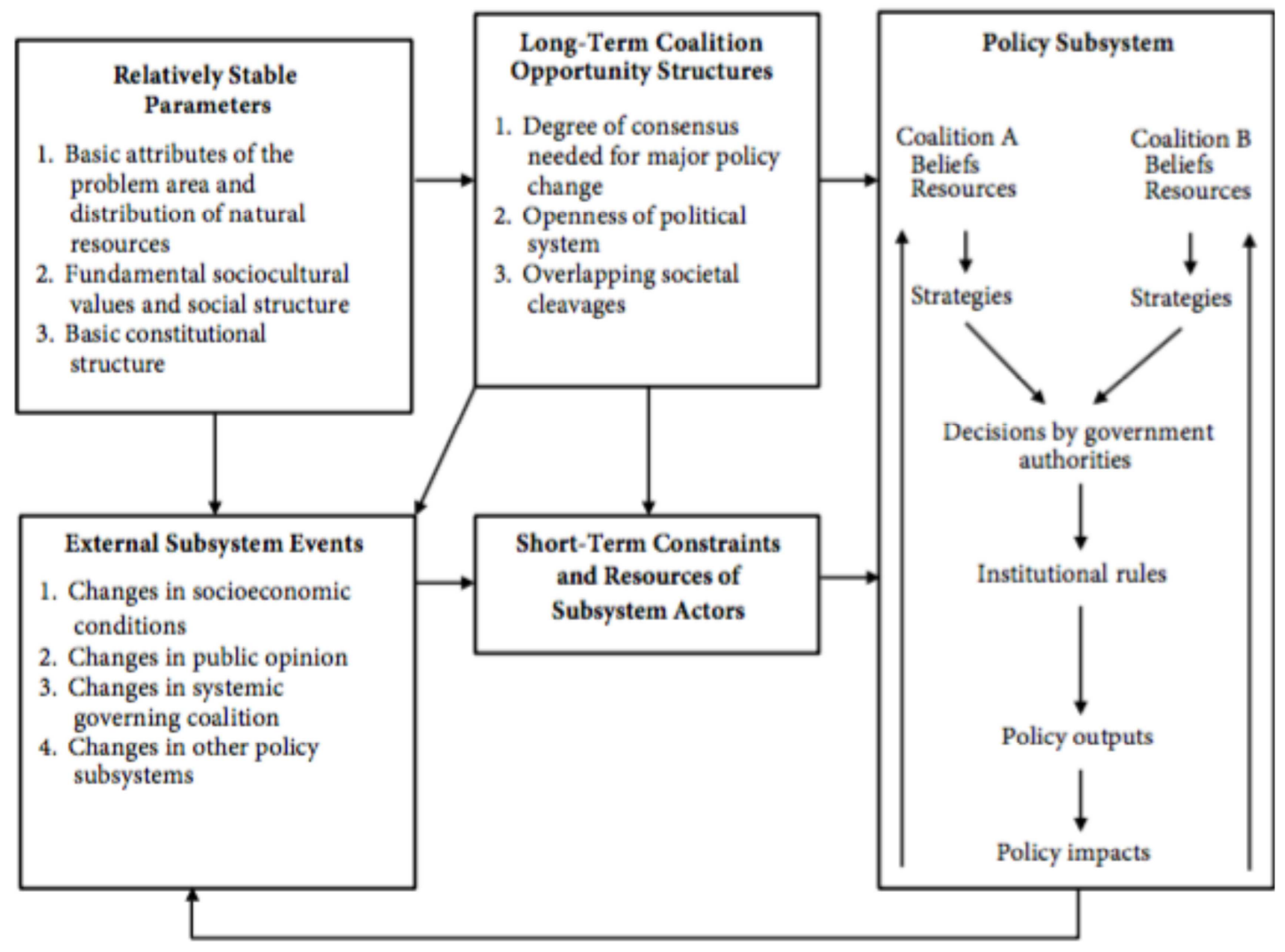

Source: Jenkins et al., 2014 [10].

Figure 1. Model of policy change。

\section{Reasons ForPolicy Change in Nigeria}

Nigeria as a country happens to be one among those countries that have good policies that are meant to bring development, but most of these policies do not stand the test of time and subsequently change by other policies. What bring about these changes of policies? This is the question which this paper seeks to answer. There are many reasons that explain policy change in Nigeria. We will briefly examine six reasons that bring about policy change in Nigeria.

\subsection{Failure of the Existing Policy to Achieve It Set Goals and Objectives}

When a policy is set in place, it is believed that it should be able to achieve its set goals and objectives. Sometimes, many policies failed to address the problems for which they were made to solve. In another words, problems still exist and even become worst while there is plan of action in existence that is meant to solve it. Let's take for instance the Nigerian educational policy of 9-3-4 and 6-3-3-4.

Before the introduction of the 9-3-4 system, the 6-3-3-4 introduced in 1982 was in operation. It is a policy in which learners are to spend 6 years in the primary school, 3 years for the junior secondary school education, and if on completion a student is discovered to have no flair for academics; such a student proceeds to spend another 3 years for vocational and technical education to acquire skills that will make the student get employed or become selfemployed. The student that shows academic flair proceeds to the senior secondary school to spend 3 years and consequently 4 years for tertiary education. The purpose for introducing this system was to infuse functionality into the Nigerian education system such that graduates of the system would be capable of using their hands, heads and heart. This system was declared as a failure by even the president of the country Ebele Jonathan (October, 2010) when he was speaking with national stake holders on the education sector. The ideal objectives which the system advocated were not realized mostly because no parent of students would want their children to stop formal school at the senior secondary school level, however, incompetent. The 6-3-3-4 was preceded by the 6-5-4 system in which a learner uses 6 years to pass through the primary education, 5 years to complete the secondary education and 4 years to go through the tertiary education program. This was the beginning of free and compulsory education emphasis at different levels by governments that ruled the country. The free and compulsory education somehow dented the competitive spirits of students with regard to entrance exams into primary and secondary schools [4]. 


\subsection{Political Instability}

Nigeria is one of the countries that was characterized with the problem of political instability particularly during military regimes. This problem had a serious effect on the nation's policies that were aimed at bringing development. If a particular policy is set in place by a particular regime in order to solve a certain problem, that set policy might likely not see the light of the day when another government comes into power. The incoming administration might either alter with the policy, remove it from being in place or change it entirely.

For instance, operation feed the nation was formulated in 1976. its major functions among others were to provide sufficient food for all Nigerians and facilitate agricultural credit from commercial banks to farmers. The policy was abandoned soon after the civilian administration of Shehu Shagari came into power in 1979 . The policy was changed with Green Revolution. And Even the green revolution did not achieve the desired result. It ended up as mere slogan or symbolic policy [3].

Political instability is also associated with lack of policy continuity. For example, when the late president Umaru Musa Yar'adua came to office, he came with 7 points agenda but after his demise, Former president Good luck Jonathan brought about transformation agenda. And now we have fighting corruption. 7 points agenda were not fully implemented and was replaced with transformation agenda: this too was not fully implemented and now we have fighting corruption as the major agenda.

Another example of policy change due to lack of continuity or political instability can be seen in Better life Program and Family Support program FSP). The program was initiated by the Nigerian government which aimed at women in the rural areas with the objective of creating awareness in women through mobilization so that they can use their potentials in bringing about national development. The program was later changed to family support in 1994 when General Sani Abacha came to power as as head of state in 1993. The family support program under the wife of the then head of head Mrs. Miriam Abacha concentrated on the family generally. The main objective of the program was to improve social and economic standard of the Nigerian family in order to realize national development. The question one should ask here is that: why the change of name in the policy despite the fact that all the policies were meant to achieve same purpose. This is as a result of the ego of our leaders, they always want to credit for themselves. It can be remembered that the interim government of Shonekan was put in place by the former head of state General Ibrahim Badamasi Babangida in 1993 and that administration was to carry out the program put in place by Mrs. Babangida which the better life program. therefore, because Meriam Abacha want to make name for herself, it was necessary for her to create new program or make changes in some areas in the ones in existence and give it a new name instead of continuing with the program initiated by the wife of the former head of state. This might account for the reasons to why there are numerous of abandoned projects in Nigeria.

\subsection{Ineffective and Corrupt Political Leadership}

Corruption has been one of the major identities of the third world countries, even though the problem is everywhere: just that the practice is more pronounce in the third world countries. Rose-ackerman [6] stated that Corruption is a symptom that something has gone wrong in the management of the state. Institutions designed to govern the interrelationships between the citizen and the state are used instead for personal enrichment and the provision of benefits to the corrupt.

In Nigeria, some policies are not really meant to benefit the masses: rather they serve as a way toward selfenrichment by those holding political power. Even those policies that are really meant to benefits the masses, some corrupt political leaders have their ways of transforming it to their personal gain. Poor governance has abandoned some important policies that will bring development to the country. Let's take for instance the privatization policy of the power sector in Nigeria. The policy was aimed at making power supply constant in Nigeria, but is unfortunate that the situation is even getting worst at this level. This is due to the fact that the major shareholders in the power holding company in Nigeria are mostly politicians: some are serving legislators or those that served before. Their major aim is profit making and therefore they will go extra mile to make sure they get it. As we can see, power distribution was privatized by the government and the same government officials are the ones that bought it. The change of this policy is to their advantage and not to the masses.

Additionally, corruption has been a serious disease in Nigeria which if dealt with will forever stagnate development of the country in all aspects. As a result of corruption, Nigeria is still under the bondage of poverty despite the fact that several efforts were made to eradicate and alleviate poverty in the country. For example, the sum of 50 billion naira was allocated to National Poverty Eradication Program (NAPEP) which was created by the then president of Nigeria President Olusegun Obasanjo administration, but this has not solved the problem of poverty but rather the situation is worsening day by day. the fact remains that most of the resources appropriated for the implementation of public policies are divided to private account, which always succeed in frustrating the implementation process.

\subsection{Policy Diffusion}

Policies are made in order to address a specific problem among a specific group of persons, but sometimes the made policies do not have direct impact on the real targeted area or population. Some people from different area ended up benefiting from the policy which were not the target. In this case, government or the custodian of the policy might decide to readdress that policy or even change it entirely.

National Commission for Nomadic Education (NCNE): It 
was enunciated in 1989 to provide basic education for nomadic herdsmen and fishermen; train nomadic teachers; provide infrastructure for the nomadic schools. Additional programs were targeted towards girl's education, women and children in exceptionally difficult circumstances, and adult literacy. The policy was targeted at the nomadic people, particularly those whose occupations are nomadic in nature. The program was absorbed by the Universal Basic Education policy. But there are no signs that the policy is functioning as planned. This is because the herdsmen who are the real target of the policy are not getting the education they ought to have [3].

\subsection{Change in Structure/Institution}

Structural change in administration, type of government and its institutions affect policies. For instance, when Nigeria adopted Federalism as a system of government, many policies that were parliamentary oriented nature have to be changed or replaced with that of federalism. Centralization of power was replaced with decentralization and this gave autonomy to order tiers of government to make plans toward addressing their problems. Unicameralism was replaced with bicameralism, office of the prime minister was replaced with that of the president, there was no longer principle of collective responsibility in the parliament because members of the executive are not members of the legislature etc. All these structural changes affect some policies that were put in place during parliamentary system of government in Nigeria.

\subsection{Socio-Economic Factors}

These factors such as unemployment, poverty, demography, ethnic and cultural diversity etc. brings about policy change. For example, Nigerian demographic and ethnic structure did not find parliamentary system of government favorable and as a result federalism is considered to be best system that will accommodate this demographic and ethnic structure of Nigeria.

More so, the unproductive over whelming population of Nigeria became a serious issue in Nigeria during the administration of former president Jonathan that he even suggested for planning as a method of birth control, though the idea was not welcomed by many Nigerians. Therefore, socio-economic changes in the society also bring about change of policy in Nigeria. In other words as things change in the society, policies in place must also be change so as to be able to address the new challenges in the society.

\section{Conclusion and Recommendation}

In conclusion, Nigeria has witnessed some policy changes, but most of these changes were as a result of political instability, poor governance, corruption and policy diffusion. Therefore, in order to address this problem: there is need for policy continuity irrespective of the person or political party in office, good governance is also required in order to monitor policy making and implementation processes and finally, policy makers and implementers should make sure that policies are implemented at the proper place.

\section{References}

[1] Capano, G. (2009). Understanding Policy Change As An Epistemological and Theoretical Problem Understanding Policy Change as an Epistemological and Theoretical Problem. Journal of Comparative Policy Analysis Research and Practice $\quad 11 \quad$ (1), 7-31. https://doi.org/10.1080/13876980802648284.

[2] Cerna, L. (2013). The Nature of Policy Change and Implementation: A Review of Different Theoretical Approaches.

[3] Obamwonyi, S. E. (2014). Public Policy Failures in Nigeria : Pathway to Underdevelopment. Public Policy and Administration Research, 4 (9), 38-44.

[4] Olaniyan, G. O. (2012). Changing Phases of Nigerian Education Policies and Challenges of Functionalism. 3 (14), 152-157.

[5] Pierce, Jonathan J, Peterson, Holly L, H. K. C. (2016). Policy Change: An Advocacy Coalition Framework Perspective Jonathan J. Pierce (Seattle University), Holly L. Peterson (Oregon State University), and Katherine C. Hicks (Seattle University) Version 8.31.16. European Consortium for Political Research General Conference, 1-37. Prague.

[6] Porter, K. M. P., Rutkow, L., \& Mcginty, E. E. (2018). The Importance of Policy Change for Addressing Public Health Problems. Public Health Reports, 133 (Supplement 1), 9-14. https://doi.org/10.1177/0033354918788880.

[7] Rose-ackerman, S. (1999). Corruption and Government Causes, Consequences, and Reform. Cambridge: Cambridge University Press.

[8] Šinko, M. (2016). Policy change - review of classification, measurement and factors. Teorija in Praksa, 53 (1), 228-247.

[9] Sabatier, P. A., and Jenkins-Smith, H. (eds). 1993. Policy Change and Learning: An advocacy coalition framework. Boulder, CO: Westview Press.

[10] Jenkins-Smith, H. C., Nohrstedt, D., Weible, C. M., \& Sabatier, P. A. 2014. "The Advocacy Coalition Framework: Foundations, Evolution, and Ongoing Research.” In Theories of the Policy Process, Third Edition edited by Paul A. Sabatier and Christopher M. Weible. Boulder, CO: Westview Press, 183-223. 